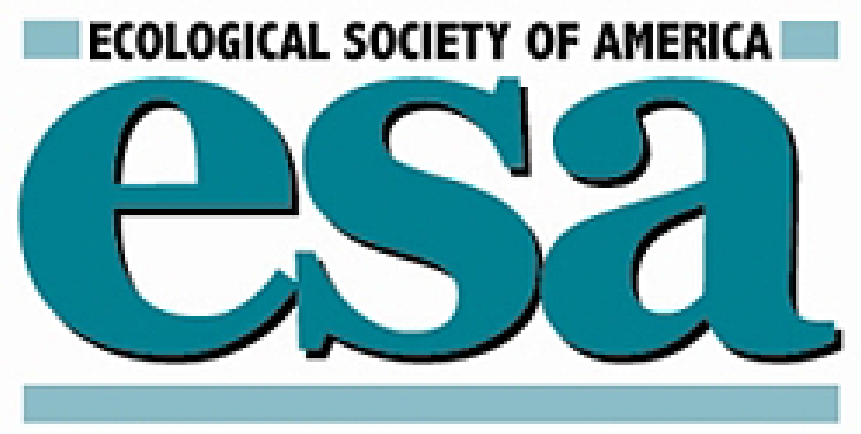

Water Relations of the Eggs of Anolis Auratus and Anolis Limifrons

Author(s): Robin M. Andrews and Owen J. Sexton

Source: Ecology, Vol. 62, No. 3 (Jun., 1981), pp. 556-562

Published by: Ecological Society of America

Stable URL: http://www.jstor.org/stable/1937721

Accessed: 13/03/2014 09:56

Your use of the JSTOR archive indicates your acceptance of the Terms \& Conditions of Use, available at http://www.jstor.org/page/info/about/policies/terms.jsp

JSTOR is a not-for-profit service that helps scholars, researchers, and students discover, use, and build upon a wide range of content in a trusted digital archive. We use information technology and tools to increase productivity and facilitate new forms of scholarship. For more information about JSTOR, please contact support@jstor.org. 
Copyright by the Ecological Society of America. Robin M. Andrews and Owen J. Sexton 1981. Water Relations of the Eggs of Anolis Auratus and Anolis Limifrons. Ecology 62:556-562. http://dx.doi.org/10.2307/1937721

\title{
WATER RELATIONS OF THE EGGS OF ANOLIS AURATUS AND ANOLIS LIMIFRONS ${ }^{1}$
}

\author{
RoBin M. Andrews \\ Department of Biology, Virginia Polytechnic Institute and State University, \\ Blacksburg, Virginia $2406 I$ USA \\ AND \\ OWen J. Sexton \\ Department of Biology, Washington University, St. Louis, Missouri 63130 USA
}

\begin{abstract}
Eggs of Anolis auratus and Anolis limifrons were incubated on soil substrates differing in matric potential of soil water. Eggs of both species hatched after a mean incubation time of $44 \mathrm{~d}$ on soils with matric potentials of $-1.48 \mathrm{MPa}$ or greater. On soils with water potentials of -2.13 and $-2.74 \mathrm{MPa}$, eggs gained in mass initially but eventually desiccated. The rate of water storage was greater for $A$. auratus eggs than for $A$. limifrons eggs on all treatments. Rates of water loss by transpiration from the surface of eggs exposed to the atmosphere was a linear function of egg mass for both species, with $A$. auratus eggs losing less water per unit time than A. limifrons eggs. Differences in water flux were correlated with eggshell morphology. Eggshells of A. auratus were thicker, had a greater density of fibrils, and had a thicker matrix of calcium carbonate than eggshells of $A$. limifrons. Thus, the eggs of $A$. auratus seem to be adapted to the dryness of their grassland habitat and the eggs of $A$. limifrons seem to be adapted to the more equitable and humid conditions of their rain forest habitat.
\end{abstract}

Key words: Anolis; egg-water relations; lizards; physiological ecology; reptilian eggs; tropics.

\section{INTRODUCTION}

Closely related species frequently exhibit physiological differences that appear to be adaptations for life in particular environments. Examples for Anolis lizards include rates of water loss (Sexton and Heatwole 1968, Gorman and Hillman 1977, Hillman and Gorman 1977) and thermoregulatory patterns (Ruibal 1961, Campbell 1971, Huey and Webster 1976). However, the ability of lizards to modify their physical environment by seeking out suitable microhabitats allows a degree of fine adjustment not possible by physiological means alone. On the other hand, the adaptations of reptilian eggs to their environments must be entirely physiological and/or morphological; after oviposition, the egg remains in the same place for the entire incubation period. Although there is an extensive literature on the physiology of reptilian eggs (Packard et al. 1977), little is known about the comparative aspects of egg physiology and morphology as adaptations to environmental conditions.

In this study, we contrast the egg-water relations of two species of tropical Anolis lizards. Anolis auratus and $A$. limifrons are sympatric in Panama, but occupy distinct habitats. Anolis auratus is restricted to open grassy areas such as pastures and roadsides while $A$. limifrons is restricted to the shaded understory of the rain forest interior. Adjacent grassland and rain forest habitats differ in their microclimatic regimes. Open

\footnotetext{
' Manuscript received 13 May 1979; revised 4 June 1980; accepted 5 June 1980.
}

habitats have higher daytime temperatures, lower relative humidity, and higher wind speeds than forested habitats in Panama (Rubinoff 1974). The post hatching stages of $A$. auratus and $A$. limifrons exhibit differences that reflect adaptations to dry and wet habitats, respectively (Sexton and Heatwole 1968, Campbell 1971, Sexton et al. 1971). Our objective was to determine if the eggs of these two species exhibit parallel physiological and morphological adaptations.

\section{Materials and Methods}

Water fluxes through eggs were evaluated using a general model for reptilian eggs (Tracy et al. 1978) which states that

$$
\dot{m}_{s t}=\dot{m}_{s}-\dot{m}_{a}
$$

where $\dot{m}_{s t}$ is the rate of change in the mass of the egg (water storage) during incubation, $\dot{m}_{s}$ is the rate of liquid water transport across the surface of the egg in contact with the substrate of the nest, and $\dot{m}_{a}$ is the rate of transpirational water exchange across the surface of the egg exposed to the atmosphere. For normal development of the embryo of at least some lizard species, the water content of the egg apparently must increase during development (Packard et al. 1977). Therefore, the rate of water uptake must be greater than the rate of water loss during incubation. Rates of water flux through the eggs of A. auratus and A. limifrons during the incubation period were measured on soils differing in matric potential. Water storage $\left(\dot{m}_{s t}\right)$ and transpirational water loss $\left(\dot{m}_{\mathrm{a}}\right)$ were measured di- 
TABlE 1. Morphological and physiological attributes of adult females, eggs, and hatchlings of the Anolis auratus and Anolis limifrons individuals used in this study.

\begin{tabular}{lcc}
\hline \hline & $A$. auratus & $\begin{array}{c}\text { A. limifrons } \\
\bar{X} \pm S_{\bar{X}}(N)\end{array}$ \\
\hline Adult females & $\bar{X} \pm S_{\bar{X}}(N)$ & \\
Snout-vent length (mm) & & $45.1 \pm 0.46(23)$ \\
Range in size (mm) & $44.9 \pm 0.46(16)$ & $41-48$ \\
Eggs & $40-47$ & \\
Mass (g) at laying & & $0.137 \pm 0.0020(52)$ \\
Shell dry mass (mg/cm $\left.{ }^{2}\right)$ & $0.164 \pm 0.0038(23)$ & $4.2 \pm 0.30(5)$ \\
Hatchlings & $5.6 \pm 0.47(5)$ & $18.8 \pm 0.14(16)$ \\
Snout-vent length (mm) & $19.4 \pm 0.09(9)$ & $0.148 \pm 0.0027(16)^{*}$ \\
Mass (g) & $0.161 \pm 0.0035(9)$ & $43.8 \pm 0.58(5)$ \\
Incubation time (d) & $44.4 \pm 0.70(9)$ & \\
\hline
\end{tabular}

* The hatchling mass data include the 5 A. limifrons individuals hatched during this study $(0.1475 \pm 0.00719 \mathrm{~g})$ and 11 individuals hatched in September and October $1972(0.1488 \pm 0.00855 \mathrm{~g} ; \mathrm{R}$. M. Andrews, personal observation $)$.

rectly, and water transport $\left(\dot{m}_{s}\right)$ was determined as the sum of these quantities.

Freshly laid eggs were used in all experiments. These were obtained from gravid females collected on Barro Colorado Island (BCI) in Panama during April and May 1977. Females were held individually in cages containing a styrofoam cup filled with damp shredded paper towels as a substrate for egg deposition. Eggs were collected daily, weighed, and marked with dots of India ink for individual recognition. One egg was obtained from each $A$. auratus female collected. The eggs (1-5) from each of 23 A. limifrons females were assigned to different treatments. Experiments for each species and soil matric potential were initiated as eggs became available; thus starting dates differed by as much as 1 mo.

Eggs were incubated under conditions of temperature and relative humidity paralleling those of natural nest sites. Eggs of $A$. limifrons are normally laid on the soil surface and covered lightly with leaf litter (Sexton et al. 1964, R. M. Andrews, personal observation). Anoles may also bury eggs in shallow nests excavated in the soil, in rotten logs, or under stones (Rand 1967, Stamps 1976). Thus the egg surface not in contact with the nest substrate is probably exposed ordinarily to high atmospheric relative humidity.

One-half litre jars were used as incubation chambers. Soil collected from the upper $1-2 \mathrm{~cm}$ of soil surface in the forest habitat of $A$. limifrons was dried to constant mass at $110^{\circ} \mathrm{C}$. Homogenous aliquots of soil $(230 \mathrm{~g})$ were placed in the chambers and distilled water was added to bring the water content (grams water per gram dry soil) to $28,32,35,39,43$, and $47 \%$. The chambers were tightly covered to reduce evaporation. During the experiments, the chambers were kept in an open-air laboratory where temperatures ranged from $23^{\circ}$ at night to $28^{\circ}$ during the day, a range comparable to air temperatures within the forest during the time of the study (Rubinoff 1974). Maximum temperatures in open areas were several degrees higher.
Changes in mass during incubation were measured for eggs buried so that one-hali of their surface area was exposed to the atmosphere and the other one-half was buried in the soil. Egg mass was determined to the nearest $0.1 \mathrm{mg}$ each $48-96 \mathrm{~h}$ during incubation. When eggs were removed for weighing, each chamber was also weighed and distilled water added if necessary to bring the chamber back to its original mass. Whether water was added or not, the soil in each chamber was stirred thoroughly to distribute the water in the soil. The chambers were checked frequently toward the end of incubation; hatchlings were removed, their mass determined to the nearest $0.1 \mathrm{mg}$, and their snout-vent length (SVL) measured to the nearest $0.5 \mathrm{~mm}$ within a few hours of hatching.

At the end of the experiments the soil used was shipped to Virginia Polytechnic Institute and State University for determination of the soil water retention curve. This curve was used to convert percent soil water to estimates of matric potential of soil water in megapascals where $1 \mathrm{MPa}=10$ bars. The conversions of percent soil water to matric potential were: $28 \%,-2.74 \mathrm{MPa} ; 32 \%,-2.13 \mathrm{MPa} ; 35 \%,-1.48 \mathrm{MPa}$; $39 \%,-0.70 \mathrm{MPa} ; 43 \%,-0.04 \mathrm{MPa}$; and $47 \%,-0.015$ MPa. For each matric potential treatment, eggs of $A$. auratus and $A$. limifrons were incubated simultaneously in the same chamber. Therefore, treatmentby-treatment comparisons of the responses of the two species are valid. However, because of day-night temperature fluctuations, condensation on the eggs may have occurred (although not observed). For this reason, the matric potentials determined for the soil and the estimated relative humidity $(98 \%$ or more under the experimental conditions, Tracy et al. 1978) may not be an exact description of conditions in the chambers at all times.

Statistical analyses of the incubation data were conducted using multivariate analysis of variance (MANOVA) techniques generalized for use with growth curves (Potthoff and Roy 1964). This analysis is to be 


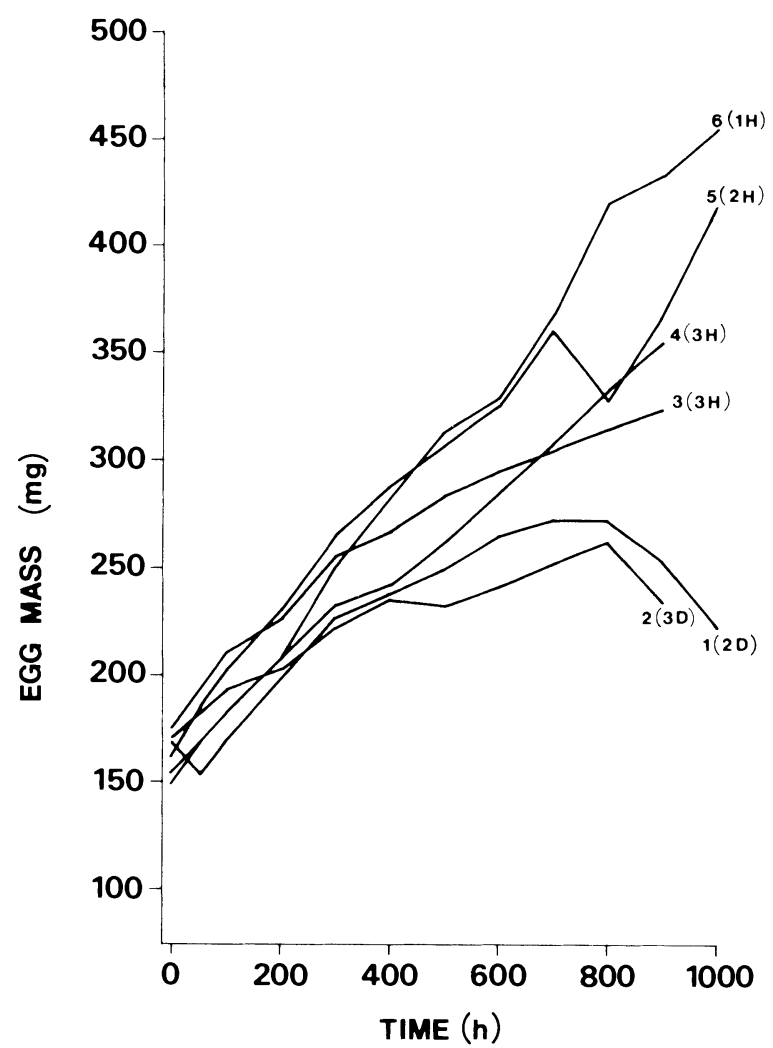

FIg. 1. Egg mass ( $\mathrm{mg}$ ) as a function of incubation time for Anolis curatus. Matric potentials in order of lowest to highest values are indicated as $1=-2.74 \mathrm{MPa}, 2=-2.13$ $\mathrm{MPa}, 3=-1.48 \mathrm{MPa}, 4=-0.70 \mathrm{MPa}, 5=-0.04 \mathrm{MPa}$, and $6=-0.015 \mathrm{MPa}$. Symbols indicating the number of eggs for each treatment and their fate are in parentheses following water potentials. Fate is indicated as $\mathrm{H}$ if the eggs hatched, $D$ if they desiccated, $M$ if the eggs were killed by mold, and $T$ for eggs transferred to a water loss experiment and not replaced.

preferred over standard regression analysis because the observations are obtained by taking repeated measurements over time on the same individual (egg). The resulting dependency of the data across time invalidates assumptions of standard regression analysis. This MANOVA analysis requires that all measurements be made at the same times. Therefore, linear interpolations were used to generate an observation at 100-h intervals for each egg.

In order to measure transpirational water losses from egg surfaces we suspended eggs of various ages on a wire rack in the $-0.7,-0.04$, and $-0.015 \mathrm{MPa}$ incubation chambers in an air-conditioned room $\left(25^{\circ}\right.$ $\pm 1^{\circ}$ ). Under these conditions, the relative humidity should have been $99 \%$ or more in all of the chambers (Tracy et al. 1978). Eggs were weighed every 6-12 h for $56 \mathrm{~h}$. The rate at which eggs lost mass stabilized at about $24 \mathrm{~h}$. Therefore, the rate of water vapor loss for each egg was determined as the slope of the line relating time and egg mass from 24 to $56 \mathrm{~h}$ based on



FIG. 2. Egg mass ( $\mathrm{mg}$ ) as a function of incubation time for Anolis limifrons. Symbol conventions as on the preceding figure. The two eggs that were killed by mold on the -0.7 MPa treatment (4) were infected after the last measurement (910 h).

five measurements per egg. Coefficients of determination $\left(R^{2}\right)$ for each egg were $85 \%$ or more in all cases. Although most of the eggs used to measure rates of water loss were acquired for this purpose only, about one-fourth of the eggs used were taken from the incubation experiments. The A. auratus eggs used were replaced in the incubation experiments. For these eggs, mass lost during the $56 \mathrm{~h}$ of total exposure to the chamber atmosphere was added to the gain in mass during incubation. The $A$. limifrons eggs used were taken from the $-0.015 \mathrm{MPa}$ treatment and were not replaced (see Results).

Egg surface area was estimated as

$$
A=4.835 m^{0.662}
$$

where $A$ is area in square centimetres and $m$ is mass in grams (Paganelli et al. 1974).

The mass of the egg shell per unit surface area at oviposition was determined for five randomly selected eggs of each species. Eggs were opened with a razor blade, their contents removed, and the shell rinsed in distilled water. The shells were dried at $60^{\circ}$ for $24 \mathrm{~h}$ and then their mass was measured.

Eggshells were examined by transmission electron microscopy for determination of their fine structure. Eggs were fixed by immersion of the entire egg for 1 $\mathrm{h}$ in $5 \%$ glutaraldehyde buffered with $0.2 \mathrm{~mol} / \mathrm{L} \mathrm{Na}$ cacodylate, $\mathrm{pH} 7.4$, containing $0.01 \mathrm{~mol} / \mathrm{L} \mathrm{CaCl}_{2}$. The eggs were removed and cut open, the contents removed, and the eggshell cut into smaller pieces which were returned to the $5 \%$ glutaraldehyde for $1 \mathrm{~h}$ at room temperature or overnight in a refrigerator. The samples were postfixed in Na-cacodylate buffered $1 \%$ $\mathrm{OsO}_{4}$ for 1-2 $\mathrm{h}$ at room temperature, dehydrated in a graded ethyl alcohol series and embedded in Spurr 
TABLE 2. Linear regression equations relating egg mass ( $m$, in $\mathrm{mg}$ ) to incubation time ( $t$, in h) for $A$. auratus and $A$. limifrons eggs incubated at four soil matric potentials. Parameter estimates were determined with a MANOVA procedure (see text for details).

\begin{tabular}{ccc}
\hline $\begin{array}{c}\text { Soil } \\
\text { matric } \\
\text { potential } \\
\text { (MPa) }\end{array}$ & Anolis auratus & Anolis limifrons \\
\hline-0.015 & $m=149.2+0.323 t$ & $m=119.6+0.187 t$ \\
-0.040 & $m=181.4+0.232 t$ & $\cdots$ \\
-0.700 & $m=159.1+0.213 t$ & $m=145.0+0.120 t$ \\
-1.480 & $m=190.0+0.173 t$ & $\ldots$ \\
\hline
\end{tabular}

resin. Thin sections were cut with a DuPont diamond knife using a Porter-Blum MT-2 ultramicrotome, stained with uranyl acetate and lead citrate, and examined with a Hitachi $\mathrm{HU}-11 \mathrm{C}$ electron microscope operated at $75 \mathrm{kV}$. Examination of fixed vs. unfixed eggshells revealed no difference in structure.

\section{RESUlts}

Anolis auratus and A. limifrons are very similar in adult size. For both species, the females from which we obtained eggs averaged $45 \mathrm{~mm}$ SVL and had nearly identical maximum SVL's (Table 1). Hatchling SVL's were not significantly different $(P>.05$, two-tailed $t$ test), averaging about $19 \mathrm{~mm}$. In contrast, both the eggs and hatchlings of $A$. auratus were significantly heavier ( $P<.01$, two-tailed $t$ tests) than those of $A$. limifrons.

Results of the incubation study are shown in Figs. 1 and 2. Eggs gained mass on all treatments, at least initially. Gain in mass was not sustained on the iwo driest soils, where loss in mass was followed by embryo death. All $A$. auratus embryos that died did so relatively late during incubation. These eggs, incubated at -2.13 and $-2.74 \mathrm{MPa}$, contained large dead embryos when the eggs were opened at the end of the normal incubation period. One of the eggs incubated at $-2.13 \mathrm{MPa}$ had been scored by the egg tooth, but the hatchling had been unable to leave the egg. In contrast, the $A$. limifrons embryos that died did so relatively early in the incubation period.

Eggs of both $A$. auratus and $A$. limifrons hatched on soils with matric potentials of $-1.48 \mathrm{MPa}$ or greater. Although all of the A. limifrons eggs incubated at $-1.48 \mathrm{MPa}$ hatched, most eggs on the three wetter treatments did not complete their development. Eggs on two of these treatments died after mold formed in the incubation chambers, and eggs could not be replaced on the remaining treatment because death of the embryos followed an experiment measuring transpirational losses. There was no difference in the incubation time for the two species $(P>.05$, two-tailed $t$ test); their combined mean incubation period was $44 \mathrm{~d}$.

In order to make statistical comparisons of the

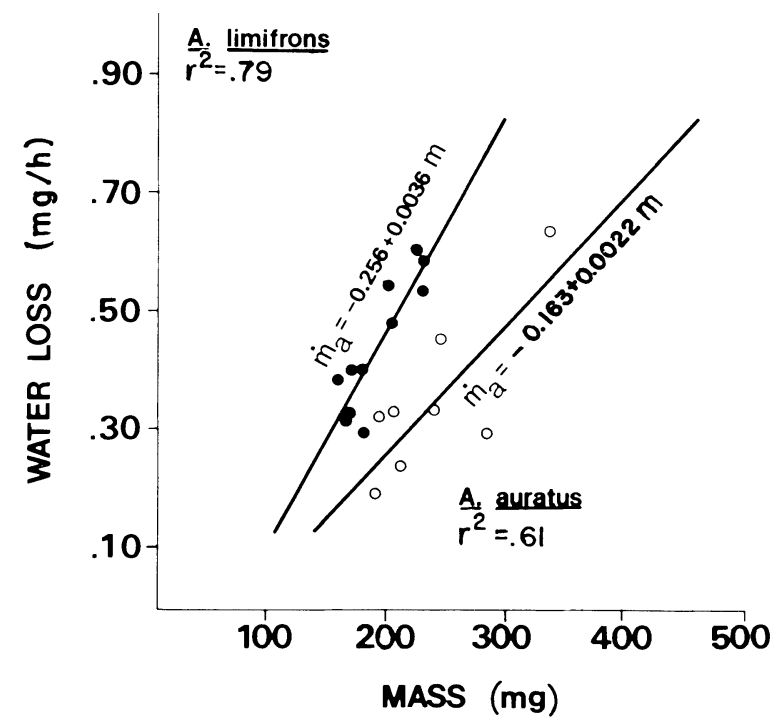

FIG. 3. The rate of transpirational water loss $\left(\dot{m}_{t}\right)$ by eggs of Anolis auratus and Anolis limifrons as a function of egg mass $(\mathrm{m})$. See text for details.

curves in Figs. 1 and 2 with the Potthoff and Roy (1964) model, the number of observations per individual must be the same. Therefore, the A. auratus data were truncated at $900 \mathrm{~h}$, the $A$. limifrons data were truncated at $700 \mathrm{~h}$ (which excluded the eggs incubated at $-0.04 \mathrm{MPa}$ ), and interspecific comparisons were truncated at $700 \mathrm{~h}$. We also excluded the data from the two driest treatments for both species because the curves were clearly nonlinear and unrelated in their response to the other curves. Polynominal regression analyses indicated that the data from the two driest treatments were best fit by second- or third-order functions.

For A. auratus eggs, simultaneous tests indicated that the rate of water storage was a linear function of incubation time on all four treatments $(P<.05)$. Moreover, the greater the water availability of the soil, the greater the rate of water storage. A simultaneous four-way test of the slopes indicated that they were unequal $(P<.025)$. However, pairwise comparisons showed that the only significant differences were between the $-0.015 \mathrm{MPa}$ treatment and the $-0.70 \mathrm{MPa}$ treatment $(P<.025)$, and between the $-0.015 \mathrm{MPa}$ treatment and the $-1.48 \mathrm{MPa}$ treatment $(P<.05)$.

For $A$. limifrons eggs, simultaneous tests indicated that the rate of water storage was not a linear function of time; the test for a quadratic term was significant $(P<.05)$. Individual tests showed that rate of water storage was a linear function of incubation time on the $-0.015 \mathrm{MPa}$ and the $-0.70 \mathrm{MPa}$ treatments $(P<$ $.05)$, but that significant quadratic terms were found on the $-0.04 \mathrm{MPa}$ and the $-1.48 \mathrm{MPa}$ treatments $(P$ $<.05$ ). Visual inspection of the data showed no apparent relationship between matric potential and $\dot{m}_{s t}$ 
TABLE 3. Rates $\left(\mathrm{mg} \cdot \mathrm{h}^{-1} \cdot \mathrm{cm}^{-2}\right)$ of water storage $\left(\dot{m}_{s t}\right)$, transpirational water loss $\left(\dot{m}_{a}\right)$, and water uptake $\left(\dot{m}_{s}\right)$ at 500 $\mathrm{h}$ of incubation for eggs of $A$. auratus and A. limifrons. See text for details.

\begin{tabular}{ccc}
\hline \hline $\begin{array}{c}\text { Soil matric } \\
\text { potential }(\mathrm{MPa})\end{array}$ & A. auratus & A. limifrons \\
\hline$\dot{m}_{s t}$ & & \\
-0.015 & .290 & .215 \\
-0.700 & .212 & .142 \\
$\dot{m}_{a}$ & & \\
-0.015 & .229 & .294 \\
-0.700 & .205 & .285 \\
$\dot{m}_{s}$ & & \\
-0.015 & .519 & .509 \\
-0.700 & .417 & .426 \\
\hline
\end{tabular}

(Fig. 2). It is possible that the conductance of the soil may have limited the transport of water (Tracy et al. 1978), clouding a steady-state correlation between matric potential and $\dot{m}_{s t}$.

The rate of increase in egg mass $\left(\dot{m}_{s t}\right)$ was greater for $A$. auratus eggs than for $A$. limifrons eggs on all treatments (Fig. 2 and Table 2). These differences were significant for the $-0.015 \mathrm{MPa}$ and the -0.70 MPa treatments $(P<.05)$. The $-0.04 \mathrm{MPa}$ and the $-1.48 \mathrm{MPa}$ treatments comparisons could not be made because of the nonlinearity of the $A$. limifrons data.

The rate of water loss by transpiration $\left(\dot{m}_{a}\right)$ was a linear function of egg mass for both species (Fig. 3). For all egg sizes, A. auratus lost less water per unit time than $A$. limifrons eggs. Moreover, the rate at which water loss increased with respect to egg mass tended to be lower for A. auratus than for A. limifrons (.10<P<.20, $t=1.43$, two-tailed test).

Eggs used in the experiment measuring transpiration ranged from 4 to $28 \mathrm{~d}$ in age. Because both age and mass increased during incubation, a correlation between these variables was expected. However, singlevariable regression analyses showed that egg mass accounted for more of the total variability in the rate of transpiration than did age. For $A$. limifrons the respective values of $r^{2}$ were .79 and .18 , and for $A$. auratus the respective values of $r^{2}$ were .61 and .57 . After accounting for mass in multiple regression analyses, age did not explain a significant proportion of the total variance in rate of transpiration for either species $(P>.05)$.

The rate of water uptake $\left(\dot{m}_{s}\right)$ was determined as the sum of water storage and water loss (from Eq. 1). Typical values for all three rates are shown in Table 3. Comparisons were made at $500 \mathrm{~h}$ of incubation on two treatments. The rate of water storage was determined from equations in Table 2 , and the rate of water loss was determined from equations in Fig. 3. The latter rate was divided by one-half since eggs in the incubation chambers had one-half of their surfaces exposed to the atmosphere. Rates are expressed per unit
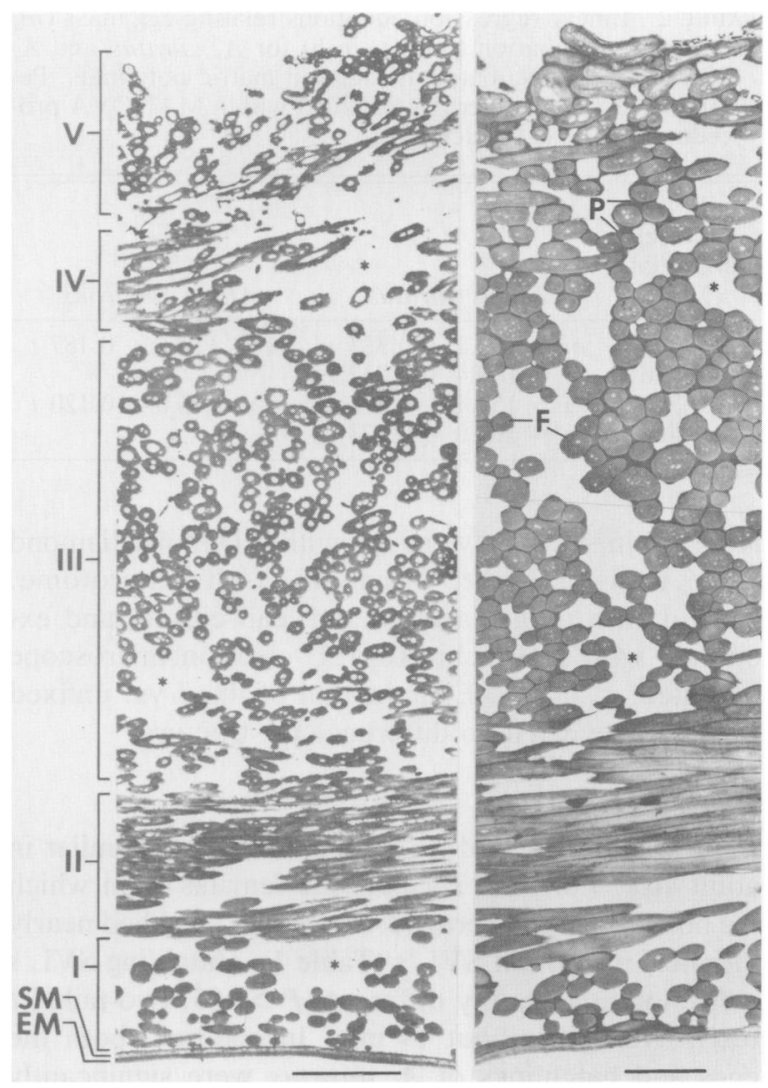

Fig. 4. Transmission electron micrograph section through the eggshells of Anolis limifrons on the left $(\times 4050)$ and $A$. auratus on the right $(\times 2775)$. The five concentric zones of fibrils are labeled from $I$ at the inner surface of the eggshell to $\mathrm{V}$ at the external surface of the eggshell. The thickness of the eggshells shown is $48 \mu \mathrm{m}$ for $A$. limifrons and $62 \mu \mathrm{m}$ for $A$. auratus. The scale at the bottom of each figure is $5 \mu \mathrm{m}$ in length. Symbols: $\mathbf{S M}=$ shell membrane, $\mathrm{EM}=$ egg membrane, $\mathrm{F}=$ fibril, $\mathrm{P}=$ perifibrillar layer, ${ }^{*}=$ interfibrillar space.

surface area of egg (Eq. 2) to facilitate comparison between the two species. Rates were divided by one-half egg surface area to express the rate of water uptake by the half of the egg exposed to the soil and the rate of water loss from the half of the egg exposed to the atmosphere. Anolis auratus eggs had higher rates of water storage and lower rates of water loss than $A$. limifrons eggs on both treatments, but a higher rate of water uptake on the wetter treatment and a lower rate of uptake on the drier treatment than the A. limifrons eggs.

The ultrastructure of the eggshells of $A$. auratus and A. limifrons is contrasted in Fig. 4. A detailed analysis of the eggshell of $A$. limifrons was conducted by Sexton et al. (1979). Therefore, only those aspects of shell morphology relevant to the present study are discussed here. The shell of both species consisted of five concentric zones of fibrils. The external surface of these fibrils was bounded by a matrix of granular 
material (calcium carbonate). The fibrils in the shells of $A$. auratus were larger and more densely packed than those in the shells of $A$. limifrons and had a thicker matrix of calcium carbonate as well. This was particularly apparent in Zone 5. Because the interfibrillar spaces are presumably the route through which water passes, the eggshells of $A$. auratus, with their relatively high fibril density, would appear to be less porous than the eggshells of $A$. limifrons. This interpretation was also supported by shell dry mass (Table 1). The eggshells of A. auratus were significantly heavier per unit surface area than the eggshells of $A$. limifrons $(P<.05$, two-tailed $t$ test $)$. The respective densities are 0.903 and $0.875 \mathrm{~g} / \mathrm{cm}^{3}$.

\section{Discussion}

Anolis auratus and A. limifrons are very similar in body size. In this study, SVL's ranged from about 19 $\mathrm{mm}$ at hatching to $48 \mathrm{~mm}$ in maximum length (see also Sexton et al. 1971, Andrews and Rand 1974). Anolis auratus individuals weigh slightly more than $A$. limifrons individuals for a given SVL over this entire range (R. M. Andrews, personal observation). Thus, the relatively large egg of $A$. auratus at oviposition probably corresponds to the material requirements of the hatchling.

For both A. auratus and A. limifrons, hatching occurred on soils with matric potentials of $-1.48 \mathrm{MPa}$ or greater. On drier soils at water potentials of -2.13 and $-2.74 \mathrm{MPa}$, all eggs stored water during the first weeks of development. Although transpirational losses on these soils eventually exceeded water uptake, the initial water storage on these extremely dry substrates would suggest that the water potential of the eggs at oviposition was $-2.74 \mathrm{MPa}$ or less. In contrast, eggs of painted turtles incubated under conditions similar to those of our experiments did not increase their net water content at matric potentials $<-0.71 \mathrm{MPa}$ (Tracy et al. 1978). Thus, lizard eggs appear to have lower water potentials at oviposition than do turtles (Tracy 1980).

For both $A$. auratus and A. limifrons, the smallest amount of water stored for eggs that hatched was about equal to the mass of the egg at oviposition. The greatest increase in egg size was observed during the incubation of an A. auratus egg at a matric potential of $-0.15 \mathrm{MPa}$. On this treatment, the egg trebled its mass and doubled its surface area. Other authors have also observed appreciable water storage by lizard egg: (Fitch and Fitch 1967, Goel 1976, Tracy 1980). Transpirational water losses increased with egg size for both species, possibly as a consequence of stretching and thinning of the shell during incubation However, even though egg age was poorly correlated with water loss through the first half of the incubation period, increasing heat production by the developing embryo might further increase transpiration rates later in the incubation period (Tracy et al. 1978).
Some comparisons between the eggs of $A$. auratus and $A$. limifrons reveal physiological and morphological differences that may represent evolutionary adjustments to habitats differing in moisture availability. A. auratus eggs exhibited a higher rate of water storage and lower rates of water uptake and transpirational water loss than eggs of $A$. limifrons. Differences in water flux were correlated with eggshell morphology. Because of their greater thickness, greater density of fibrils, and a thicker matrix of calcium carbonate, the eggshells of $A$. auratus may provide more resistance to the movement of water than those of $A$. limifrons. Thus, the eggs of $A$. auratus seem to be adapted to the dryness of their grassland habitat. For A. auratus, water is rapidly stored at high matric potentials because of low transpirational water losses from the exposed egg surface. Low rates of water loss by transpiration also mean that embryos can survive relatively long periods of desiccation. For example, eggs incubated on the two driest soils in the present study possibly could have completed development if water had become more available during the latter third of the incubation period. In contrast, the eggs of $A$. limifrons seem to be adapted to the relatively high and stable water regimes of the forest interior. Although the rate of water uptake was high on soils where hatching occurred, the net result of high transpirational losses was a low rate of water storage. Eggs of $A$. limifrons cannot survive long periods of desiccation; embryo death occurred within the first third of the incubation period on the two driest soils used in this study.

\section{ACKNOWLEDGMENTS}

Work in Panama by R. M. Andrews was supported by National Science Foundation Grant Number 76-05758 and a Smithsonian Research Award, both to Dr. A. S. Rand of the Smithsonian Tropical Research Institute. Studies on egg morphology by O. J. Sexton were supported by the Department of Biology, Washington University. Michael Veith, Department of Biology, Washington University, did the electron microscopy of the eggshells. We would also like to thank N. Fetcher, G. C. Packard, and A. Muth for their many helpful comments on the manuscript, D. F. Amos for determining the soil water retention curve, $\mathrm{R}$. Kimsey for weighing eggs on several dates, J. B. Birch and J. Stewart of Virginia Polytechnic Institute and State University for conducting the MANOVA analyses, and J. Travis for bringing the Potthof and Roy reference to our attention.

\section{Literature Cited}

Andrews, R. M., and A. S. Rand. 1974. Reproductive effort in anoline lizards. Ecology 55: 1317-1327.

Campbell, H. W. 1971. Observations on the thermal activity of some tropical lizards of the genus Anolis. Caribbean Journal of Science 11:17-20.

Fitch, H. S., and A. V. Fitch. 1967. Preliminary experiments on physical tolerances of eggs of lizards and snakes. Ecology 48: 160-165.

Goel, S. C. 1976. On the mechanism of water uptake by the developing eggs of Calotes versicolor. Experientia 32: $1331-1333$.

$\rightarrow$ Gorman, G. C., and S. Hillman. 1977. Physiological basis 
for climatic niche partitioning in two species of Puerto Ri. $\rightarrow$ Sexton, O. J., and H. Heatwole. 1968. An experimental incan Anolis (Reptilia, Lacertilia, Iguanidae). Journal of vestigation of habitat selection and water loss in some anHerpetology 11:337-340.

Hillman, S. S., and G. C. Gorman. 1977. Water loss, desiccation tolerance, and survival under desiccating conditions in 11 species of Caribbean Anolis. Oecologia 29:105116.

$\rightarrow$ Huey, R. B., and T. P. Webster. 1976. Thermal biology of Anolis lizards in a complex fauna: the cristatellus group on Puerto Rico. Ecology 57:985-994.

Packard, G. C., C. R. Tracy, and J. J. Roth. 1977. The physiological ecology of reptilian eggs and embryos, and the evolution of viviparity within the class Reptilia. Biological Reviews 52:71-105. oline lizards. Ecology 49:762-769.

Sexton, O. J., H. Heatwole, and D. Knight. 1964. Correlation of microdistribution of some Panamanian reptiles and amphibians with structural organization of the habitat. Caribbean Journal of Science 4:261-295.

Sexton, O. J., E. P. Ortleb, L. M. Hathaway, R. E. Ballinger, and P. Licht. 1971. Reproductive cycles of three species of anoline lizards from the Isthmus of Panama. Ecology 52:201-215.

Sexton, O. J., G. M. Veith, and D. M. Phillips. 1979. Ultrastructure of the eggshell of two species of anoline lizards. Journal of Experimental Zoology 207:227-236.

$\rightarrow$ Paganelli, C. V., A. Olszowka, and A. Ar. 1974. The aviar egg: surface area, volume, and density. Condor 76:319325.

$\rightarrow$ Potthoff, R. F., and S. N. Roy. 1964. A generalized multivariate analysis of variance model useful especially for growth curve problems. Biometrika 51:313-326.

Stamps, J. A. 1976. Egg retention, rainfall and egg laying in a tropical lizard, Anolis aeneus. Copeia 1976:759-764.

Tracy, C. R., G. C. Packard, and M. J. Packard. 1978. Water relations of chelonian eggs. Physiological Zoology 51:378-387.

$\rightarrow$ Rand, A. S. 1967. Communal egg laying in anoline lizards. Herpetologica 23:227-230.

Rubinoff, R. W., editor. 1974. Environmental monitoring and baseline data (1973). Smithsonian Institution, Washington, District of Columbia, USA.

$\rightarrow$ Tracy, C. R. 1980. Water relations of parchment-shelled lizard (Sceloporus undulatus) eggs. Copeia 1980:478-482. 